\title{
Correction
}

\section{Correction: Goulas et al., Unravelling the Intrinsic Functional Organization of the Human Lateral Frontal Cortex: A Parcellation Scheme Based on Resting State fMRI}

In the article "Unravelling the Intrinsic Functional Organization of the Human Lateral Frontal Cortex: A Parcellation Scheme Based on Resting State fMRI" by Alexandros Goulas, Harry B. M. Uylings, and Peter Stiers, which appeared on pages 10238-10252 of the July 25, 2012 issue, the authors noticed some references should be modified/omitted from the references as listed below. This error (and its correction) does not affect the scientific integrity of the data in particular and that of the paper in general.

These references should be omitted:

Munkres J (1957) Algorithms for the assignment and transportation problems. J Soc Ind Appl Math 5:32-38.

Badre D, D’Esposito M (2007) Functional magnetic resonance imaging evidence for a hierarchical organization of the prefrontal cortex. J Cogn Neurosci 19:2082-2099.

Goldman-Rakic PS (1988) Topography of cognition: parallel distributed networks in primate association cortex. Annu Rev Neurosci 11:137-156.

This reference should be added:

Von Stein A, Sarnthein J (2000) Different frequencies for different scales of cortical integration: from local gamma to long range $\alpha /$ theta synchronization. Intern J Psychophysiol 38:301-313.

This reference should be replaced:

Rajkowska G, Goldman-Rakic PS (1995) Cytoarchitectonic definition of prefrontal areas in the normal human cortex. I. Remapping of areas 9 and 46 using quantitative criteria. Cereb Cortex 5:307-322.

with:

Rajkowska G, Goldman-Rakic PS (1995) Cytoarchitectonic definition of prefrontal areas in the normal human cortex: II Variability in locations of areas 9 and 46 and relationship to the Tailarach coordinate system. Cereb Cortex 5:323-337.

Reference-related typos:

(Yeterian et al., 2011) should read (Yeterian et al., 2012) (p. 10238), (Iturria-Medina, 2010) should read (Iturria-Medina et al., 2011) (p. 10242), (Zhang et al., 2009) should read (Zhang et al., 2010) (p. 10240), (Hutchison et al., 2011) should read (Hutchison et al., 2012) (p. 10242), (Petrides et al., 2011) should read (Petrides et al., 2012) (p. 10250), (Zilles and Amunts, 2011) should read (Zilles and Amunts, 2010) (p. 10248).

DOI: 10.1523/JNEUROSCI.0257-13.2013 